\title{
Ascending tones as signifiers of cultural identity in northern England
}

\author{
Malvina Aleksandrovna Demina ${ }^{1,2^{*}}$ and Polina Kirillovna Shishova ${ }^{2}$ \\ ${ }^{1}$ Moscow State Linguistic University, Department of English Phonetics, Moscow, Russia \\ ${ }^{2}$ Financial University under the Government of the Russian Federation, Department of Foreign \\ Languages and Intercultural Communication, Moscow, Russia
}

\begin{abstract}
This study investigates prosodic patterns in dialects of Manchester, Liverpool, Newcastle and Leeds that distinguish northern English pronunciation from other regional types. The authors argue that melodic cues can act as signifiers of northern English cultural identity. The empirical research included auditory and acoustic analyses of authentic speech recordings of four female and four male speakers from the listed above urban centres in northern England. The research primarily concerned intonational means and prosodic parameters of fundamental frequency (F0) and pitch range. The findings revealed both individual characteristics of each dialect and regional distinctive features common for northern speech in general with a special regard to intergender variation. The results of the research showed that the distribution of melodic patterns in northern English speech is different from the standard British pronunciation and is mainly characterized by the frequent use of rising contours in affirmative utterances. The detailed acoustic analysis of configuration and pitch range of such ascending tunes allowed the authors to describe four main variants of rising intonation in final sense-groups of declaratives. These specific melodic cues of oral speech make it possible to identify a northerner and take into account this sociocultural context, as well as other conventional implicatures in the process of cross-cultural verbal interaction.
\end{abstract}

Keywords: northern English dialects, cultural identity, rising tone, pitch range, fundamental frequency

\section{Introduction}

Recent years have seen a flourishing of sociolinguistic research on the language variation and linguistic expressions of identity accounting for numerous pitfalls and misunderstandings of cross-cultural communication [1-3]. This profound interest of a significant number of research papers in regional language varieties has been largely encouraged by the development of such social tendencies as tolerance, inclusiveness, egalitarianism. Dialectal speech, therefore, is viewed as a social phenomenon that reflects a speaker's identity verbally $[4,5]$.

*Corresponding author: demina.malvina@gmail.com 
In linguistic studies, it is well established that language is central to how people portray themselves and perceive their interlocutors $[6,7]$. In this respect, the speaker's prosodic aspects of speech behaviour, recognized as the most difficult features to control in the process of communication, might be taken by the listener to be a more foolproof indicator of the speaker's cultural background than are other verbal and behavioral cues. Therefore, prosodic and intonational means possess unusual potential to reveal the processes of construction and negotiation of identity and human relations with perceptions of sameness and difference among social groups at the core of these issues.

As is well-known, each region of Britain has its own cultural, social, and linguistic features that form an interconnected convergence. An example of such is the phenomenon of the traditional opposition of north and south in England, i.e. the so-called North-South Divide. However, today nobody in England thinks of this situation as of explicit confrontation between the regions $[8,9]$. The term reflects a sort of historically established cultural division still present in the country into two major groups or rather socio-cultural communities traditionally living in the north and the south of England and refers to a kind of 'friendly rivalry' between the two regions, rather than anything else.

English north is described as a region of great contrasts and such huge industrial conurbations as Newcastle, Leeds, Liverpool and Manchester. However, among the English themselves there is no unanimous consent on the geographical line between the north and the south [10]. Thereby, it is fair to conclude that a northerner's identity lies more in the social self-determination of a person rather than in their regional roots and geographical settlement.

Distinctive segmental features of northern dialects have received a comprehensive description in sociolinguistic and perception dialectology studies. All of them assert that the phrase 'northern accent' is popularly used for the kind of speech heard over a large area of England characterized by a rich mosaic of regional variation in pronunciation. According to Collins and Mees' data, perhaps as many as ten million people speak Northern English, making it the second most widely spoken variety in Britain [11]. Therefore, researchers currently define two competing mainstream sub-systems of the language in England, each reflecting strong cultural identity of the speakers [12]. This phonological antagonism of two large geographical areas, formed in part from differing economic experiences associated with the historical development of the industrial revolution, clearly manifests itself in the vocalic variation across these territories, namely the absence of phonological contrasts FOOT-STRUT and TRAP-BATH in Northern English phonemic inventory. Wells, in his landmark three-volume book "Accents of English" (1982), introduced his widely adopted comprehensive system of 24 keywords, each referring to a set of words sharing a certain phonetic context for a particular stressed vowel. Under his system, the lexical set FOOT, for example, indicates the vowel in such words as full, look, could, and STRUT denotes the vowel in, for example, cub, rub, hum [13].

If segmental phonological features of Northern English deserved detailed attention in extensive experimental research [14-16], suprasegmental characteristics of northern speech have not been sufficiently described yet, thus, leaving a rich and fruitful area for future linguistic insights on the subject. Intonation, meanwhile, bears a crucial role in the correct interpretation of the message [17], which is especially important for regional speech in the context of intercultural communication, since its prosodic properties presumably may deviate significantly from the standard pronunciation.

\section{Methods}


The experimental corpus of the study included eight authentic interviews of Northern English male and female speakers aged 25-39, living in the biggest urban centers in the northern part of the country (Liverpool, Manchester, Leeds and Newcastle), with a total duration of about 40 minutes. The informants were of the same ethnicity, language experience, level of education, and socioeconomic status. The main research methods were auditory and acoustic analyses of selected speech samples with subsequent quantitative processing of the data obtained. The auditory analysis of speech samples made it possible to preliminarily determine the main tendencies in the intonation of northern dialects and select specific intonation groups for further verification in the course of detailed acoustic analysis. The key prosodic parameter for acoustic analysis using PRAAT version 6.0.33 software was the fundamental frequency (F0max and F0min in Hz) that was measured in the selected intonation groups, as well as throughout the whole speech of the informants.

\section{$3 \quad$ Results and Discussion}

The results of the auditory analysis conducted at the first stage of the investigation revealed that northern speech is characteristic of rather frequent use of ascending terminal contours in affirmative utterances (Table 1), which clearly distinguishes Northern English dialects from the standard pronunciation in which rising tones mainly perform their referring function [18] and are normally used in non-final sense-groups or in interrogative utterances.

Table 1. Terminal contours in the northern speech samples (\%).

\begin{tabular}{|l|c|c|c|c|}
\hline \multicolumn{1}{|c|}{ Dialect } & Rising & Falling & Falling-Rising & Rising-Falling \\
\hline \multicolumn{5}{|c|}{ Female speakers } \\
\hline LEEDS & 24 & 76 & 0 & 0 \\
\hline LIVERPOOL & 13 & 69 & 0 & 18 \\
\hline NEWCASTLE & 32 & 48 & 8 & 12 \\
\hline MANCHESTER & 20 & 67 & 13 & 0 \\
\hline & & Male speakers & 0 \\
\hline LEEDS & 57 & 38 & 5 & 7 \\
\hline LIVERPOOL & 35 & 48 & 10 & 18 \\
\hline NEWCASTLE & 33 & 39 & 10 & 4 \\
\hline MANCHESTER & 30 & 64 & 2 & \\
\hline
\end{tabular}

This very specific use of ascending contours in the proclaiming function, normally assigned to falling tones only, may serve as a bright signifier of northern identity of the speaker.

The use of rising or referring tones was mentioned by Thorne [19] and Cruttenden [20]. The latter suggests that the use of rising intonation in these areas is due to an indirect Celtic influence caused by an influx of people from Ireland and Scotland. 
Interestingly enough, the findings of our experiment show that in each region rising terminal tones are more frequently used in masculine speech (Table 1). This could testify to men's speech being more melodic and less assertive, as contrasted to the women's manner. This assumption was tested at the second, acoustic, stage of the experiment that allowed to objectively assess the overall pitch range of northern masculine and feminine speech (Fig. 1). The obtained data, indeed, proved a wider pitch range and greater melodic variation of the male respondents' speech due to the frequent use of salient ascending contours. The female informants on the contrary demonstrate instances of rather 'flat' intonation.

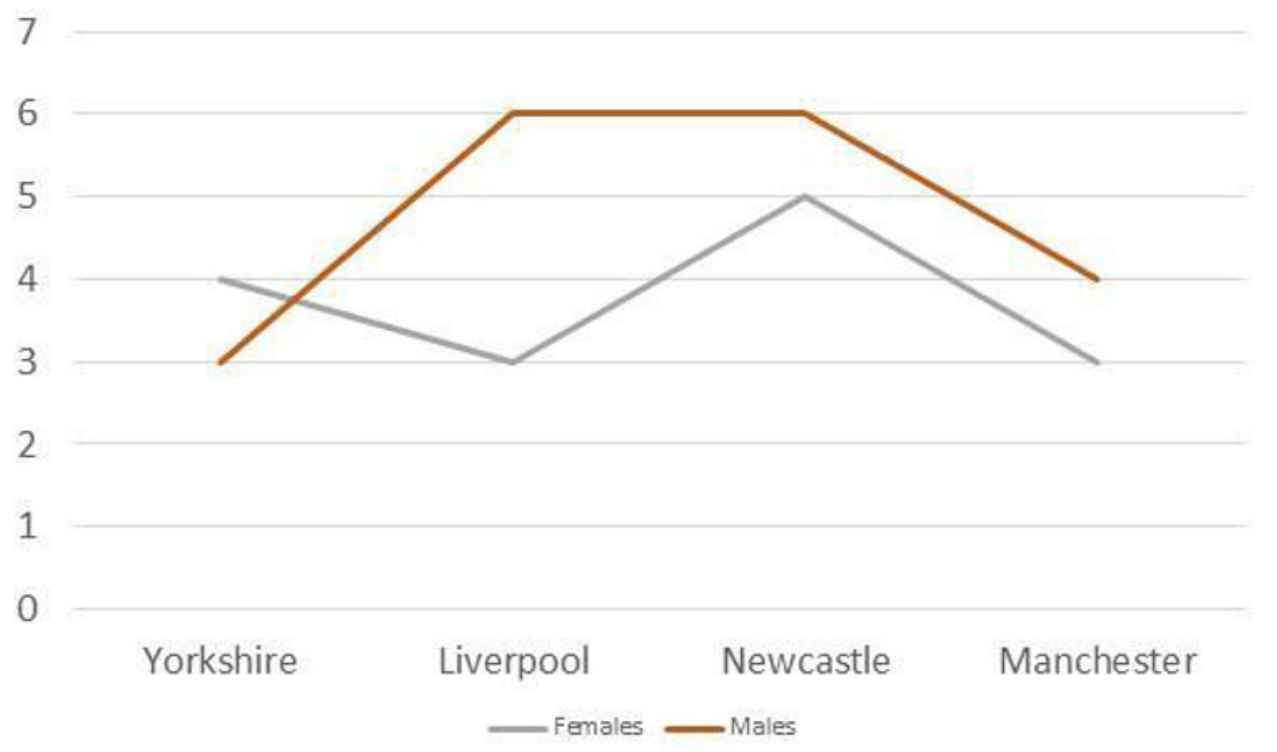

Fig 1. Pitch range in the northern speech samples (st).

The acoustic stage of the experiment also implied further detailed study of such melodic parameters of the selected rising terminal tones as fundamental frequency (F0) and pitch range. The obtained data made it possible to distinguish four main categories of ascending contours in the northern speech samples according to their F0min and F0max values (Table 2).

Table 2. Melodic characteristics of terminal rising contours in the northern speech samples.

\begin{tabular}{|l|c|c|c|c|}
\hline \multicolumn{1}{|c|}{ Contour } & F0min (Hz) & F0max (Hz) & F0mean (Hz) & Range (st) \\
\hline \multicolumn{5}{|c|}{ Female speakers } \\
\hline LEVEL RISE & 159 & 255 & 186 & 8 \\
\hline HIGH RISE & 203 & 256 & 230 & 4 \\
\hline MID RISE & 164 & 193 & 179 & 3 \\
\hline LOW RISE & 104 & 142 & 123 & 5 \\
\hline \multicolumn{5}{|c|}{ Male speakers } \\
\hline
\end{tabular}




\begin{tabular}{|l|c|c|c|c|}
\hline LEVEL RISE & 120 & 159 & 140 & 5 \\
\hline HIGH RISE & 133 & 174 & 154 & 5 \\
\hline MID RISE & 119 & 143 & 131 & 3 \\
\hline LOW RISE & 110 & 136 & 123 & 4 \\
\hline
\end{tabular}

Figures 2 and 3 demonstrate that generally masculine speech shows a more systematic distribution of rising tones in each analyzed northern accent, which could also contribute to a greater melodic variability of masculine northern speech mentioned above.

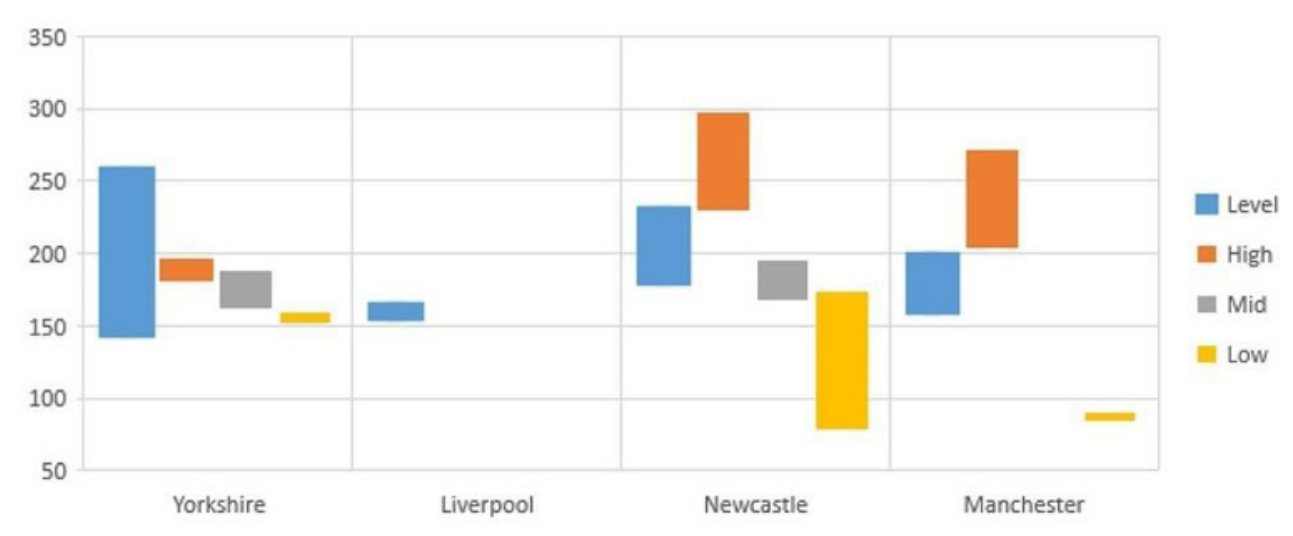

Fig. 2. The F0 values of rising tones in female northern speech (Hz).

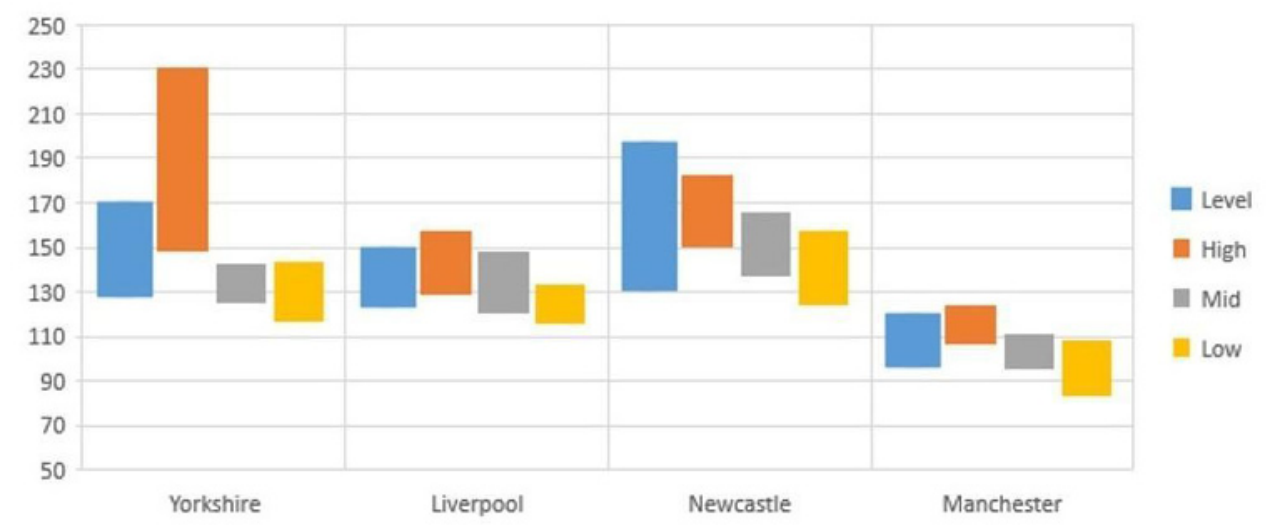

Fig. 3. The F0 values of rising tones in male northern speech $(\mathrm{Hz})$.

As for distinctive melodic characteristics of each dialect, the obtained data reveals that F0 parameters of terminal rising tones in the speech of both respondents from Newcastle have a more systematic distribution, as compared to the other regions. The geographical proximity of the region to Scotland may have had its impact on the prosodic specifics of Newcastle speech [14]. Scottish intonation, for instance, in Glasgow is noteworthy for terminal rising patterns [21]. 
The ascending melody in the speech of the informants from Liverpool appeared to be rather "flat" and inexpressive. Such findings may testify to the process of levelling [15] of rising patterns in the region with the predominant use of Level rising tune that has a more levelled tonic movement and a linear configuration.

A wider Level Rise is present in the speech of the respondents from Yorkshire. According to the findings, this type of tone is prevailing in the female speech, as its frequency constitutes $57 \%$ (Fig. 4). The male speech in the region is more characterized by the frequent use of Mid Rises (47\%). Moreover, the pitch values of High rising tones in the male speech sample appear to be the highest in terms of intragender variation across the northern region (Figs. 3, 5).

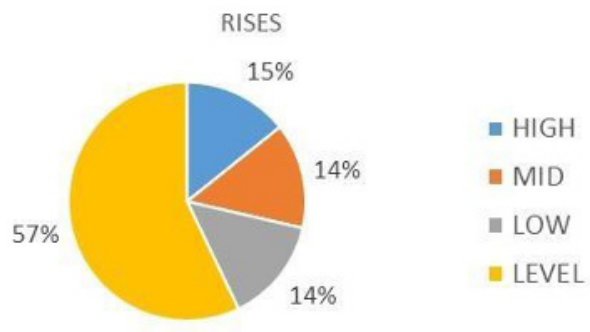

Fig. 4. Rising tones in the speech of a female from Leeds.

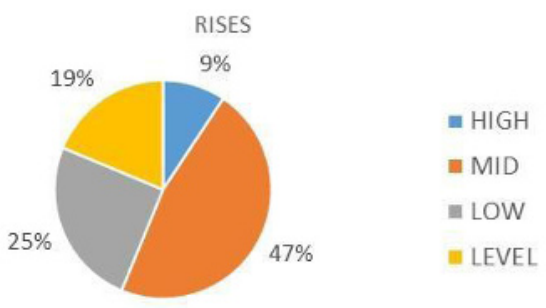

Fig. 5. Rising tones in the speech of a male from Leeds.

The registered distribution of melodic patterns in Yorkshire may, however, reflect modern international trends extending across geographical areas, social classes, the gender and age boundaries, particularly the so-called 'Upspeak', described as the use of high termination in the final tone unit in a declarative clause. Upspeak has an 'affective dimension', acting as a bonding technique to promote a sense of solidarity and empathy between speakers and listeners [22]. The expressed assumption is mainly grounded on the fact that Yorkshire has never been referred by dialectologists to those Celtic-influenced traditional varieties that employ a final rising tone where a falling tone would be expected in RP [23].

Regarding Manchester, the registered rising tones in the speech samples are realized on a lower pitch level compared to the other northern speakers' data. In addition, the informants used Low and Mid Rises more frequently than the other types. This, however, may be an individual vocal characteristic of the respondents, rather than a specific regional melodic feature.

\section{Conclusion}


This article reports the results of a phonetic study of distinctive melodic features of northern English speech in four main urban centers (Manchester, Liverpool, Leeds and Newcastle). It concludes that a frequent occurrence of terminal ascending contours in declarative clauses contributes to the specific colouring of the northern English speech and serves as a clear signifier of the cultural identity of the northerners.

Unique melodic patterns in Northern English dialects that resulted as an inevitable consequence of the historical development of Britain, have acquired a special role of a sociocultural marker of the region. Thus, it is possible to conclude that suprasegmental features of regional speech have their noticeable impact in the verbal manifestation of self-identification of a speaker and actively participate in the processes of constructing and signaling cultural identity in the context of intercultural communication.

\section{References}

1. C. Meierkord, E.W. Schneider (eds), World Englishes at the Grassroots (Edinburgh University Press, 2021)

2. P. Peters, K. Burridge (eds), Exploring the Ecology of World Englishes in the Twenty-first Century (Edinburgh University Press, 2021)

3. B. Spolsky, Rethinking Language Policy (Edinburgh University Press, 2021)

4. H. Tajfel, Interindividual behaviour and intergroup behaviour, in H. Tajfel (ed), Differentiation between Social Groups: Studies in the Social Psychology of Intergroup Relations, 27-60 (Academic Press, London, 1978)

5. P. Honeybone, W. Maguire (eds), Dialect Writing and the North of England (Edinburgh University Press, 2020)

6. M. Meyerhoff, Introducing Sociolinguistics (Routledge. Taylor \& Francis Group, London, New York, 2011)

7. D. Watt, C. Llamas (eds), Language, Borders and Identity (Edinburgh University Press, 2014)

8. D.E. Ager, Ideology and Image. Britain and Language (Multilingual Matters Limited, 2003)

9. K. Wales, Northern English: A Social and Cultural History (Cambridge University Press, 2009)

10. P. Trudgill, The Dialects of England (Blackwell Publishers Ltd, Oxford, 1999)

11. B. Collins, I.M. Mees, Practical Phonetics and Phonology. A Resource Book for Students (Taylor \& Francis, 2008)

12. M.A. Demina, Russian Linguistic Bulletin, 2(10), 51-55 (2017). https://dx.doi.org/10.18454/RULB.1

13. J.C. Wells, Accents of English 2. The British Isles (Cambridge University Press, 1982)

14. G.J. Docherty, Derby and Newcastle: instrumental phonetics and variationist studies, in P. Foulkes, G.J. Docherty (eds), Urban voices. Accent Studies in the British Isles, 47-71 (Routledge, London, New York, 1999)

15. P. Kerswill, A. Williams, Dialect levelling: change and continuity in Milton Keynes, Reading and Hull, in P. Foulkes, G.J. Docherty (eds), Urban voices. Accent Studies in the British Isles, 135-147 (Routledge, London, New York, 1999) 
16. R. Alcorn, et al. (eds), Historical Dialectology in the Digital Age (Edinburgh University Press, 2019)

17. M.A. Demina, XLinguae, 15, 142-156 (2021). https://doi.org/10.18355/XL.2021.14.02.11

18. D. Brazil, The Communicative Value of Intonation in English (Cambridge University Press, 2004)

19. S. Thorne, West Midlands English, in T. Hopkins, J. McKenny (eds), World Englishes. Volume I: The British Isles, 138-164 (Bloomsburry Academic, London, 2017)

20. A. Cruttenden, Rises in English, in J. Windsor-Lewis (eds), Studies in General and English Phonetics, 155-173 (Routledge, London, 1995)

21. J. Corbett, J. Stuart-Smith, English in Scotland, in T. Hopkins, J. McKenny (eds), World Englishes. Volume I: The British Isles, 192-219 (Bloomsburry Academic, London, 2017)

22. B. Bradford, The Rise of Upspeak, in B. Collins, I.M. Mees (eds), Practical Phonetics and Phonology. A Resource Book for Students, 248-253 (Routledge, London, New York, 2008)

23. A. Hughes, P. Trudgill, D. Watt, English Accents and Dialects (Holder Education, London, 2012) 